\title{
DESIGN, CONSTRUCTION AND PERFORMANCE STUDY OF A CASCADE IMPACTOR FOR REDUCING DIESEL PARTICULATE EMISSION
}

\author{
Md. Shamim Akhter*, S.M. Najmul Hoque and Md. Nurun Nabi \\ Department of Mechanical Engineering, \\ Rajshai University of Engineering and Technology, Rajshahi-6204. \\ "E-mail: mdakhter3456@yahoo.com
}

\begin{abstract}
In this paper, the design and construction of a cascade impactor for reducing particulate emission from a diesel engine exhaust has been presented and experiments have been carried out to determine its collection efficiency. The cascade impactor designed in this work consists of four stages having successive decreasing nozzle diameter so as to capture successive smaller diameter particles in the stages. The successive nozzle diameters $(D)$ were selected $2.1 \mathrm{~cm}, 1.7 \mathrm{~cm}, 1.3 \mathrm{~cm}$ and $0.9 \mathrm{~cm}$. Also the distances between nozzle and impaction plate $(S)$ were taken as $2.1 \mathrm{~cm}, 1.4 \mathrm{~cm}, 0.9 \mathrm{~cm}$ and $0.45 \mathrm{~cm}$ respectively so that $S / D$ for succeeding stages becomes 1, 0.82, 0.7 and 0.5 respectively. In this investigation, collection efficiency of the cascade impactor based on different engine operating conditions has been determined. Effect of fitting the cascade impactor to engine exhaust on different engine parameters and engine emissions were also found out. At a constant speed of $1000 \mathrm{rpm}$, a maximum collection efficiency of about $85 \%$ of the impactor was obtained at a load of $6 \mathrm{~kg}$. A slight decrease in brake thermal efficiency of the engine with the cascade impactor was also noticed. However, by fitting the cascade impactor to the engine, CO and NOx emissions were found to decrease.
\end{abstract}

Keywords: Real impactor, cascade impactor, Reynolds number, Stokes number, collection efficiency.

\section{INTRODUCTION}

A suspension of solid or liquid particles in a gas is called aerosol ${ }^{1}$. The term aerosol includes both the particles and the suspending gas, which is usually air. Particles size ranges from 0.001 to over $100 \mu \mathrm{m}$. Aerosols are produced by natural processes and by people, both intentionally and unintentionally as a by-product of their activities. Smoke, dust, fume, mist, fog, smog, cloud etc are all common aerosols found in nature. Transport technology is one of the technologies which have changed human civilization.

The transport technology is mainly based on the internal combustion powered by petrol and diesel engines. The main pollutants contributes by the automobiles are CO, UBHC (Unburned-hydro-carbon), NOx, lead and particulate matter. Diesel exhaust is a major contributor to various types of air pollution including smog forming NOx and fine particles. Exhaust from heavy-duty diesel engines contains between 100 to 200 times more small particles than gasoline engine ${ }^{2}$. It has been found that the major source $(67 \%)$ of air pollution in major cities is emissions from automobiles ${ }^{3}$. In Bangladesh, due to rapid and unplanned urbanization the total number of vehicles has increased enormously. The largest polluters are trucks and buses. They produce a large amount of particulate emissions.

Devices used to control the particulate emission from many sources are inertial impactors. Inertial impactors are popular instruments for the collection and size classification of airborne particles. Various types of impactor are real impactor, cascade impactor and virtual impactor. The most common type of real impactor consists of a single jet of particle-laden gas (aerosol) impinging upon a flat plate as shown in Figure 1. Particles larger than

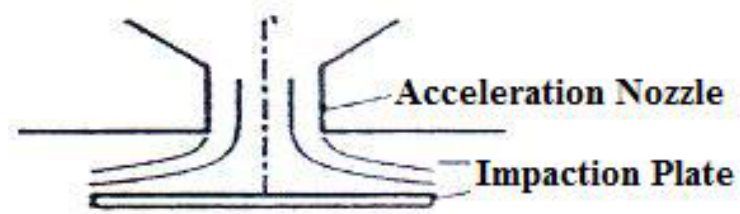

the cut-size of the impactor will slip across the streamlines and impact upon the plate while smaller particles will flow the streamlines and are not collected. The most important impactor characteristic is its collection efficiency. The collection efficiency is defined as a fraction of particles passing through the nozzle that are collected upon the impaction plate. The ideal impactor has a perfectly sharp efficiency curve i.e.; all particles larger than the cut-size of the impactor are collected on the plate, while all smaller particles follow the gas flow and pass out of the impaction region.

A cascade impactor consists of a number of real impactors having successive decreasing nozzle diameter arranged in series and Due to its simple design, low cost and effective performance, cascade impactors are widely used for: industrial hygienic studies, Indoor Air Quality (IAQ) studies, outdoor ambient sampling, air pollution studies, inhalation toxicology and epidemiological studies, aerosol research and pharmaceutical studies ${ }^{4}$.

\section{DESIGN AND CONSTRUCTION}

The most important parameters ${ }^{5}$ in the design of a stage in a cascade impactor are

i. Ratio of jet-to-plate distance to the nozzle diameter (S/D),

ii. Jet Reynolds number (Re) and

iii. Stokes number $\left(\mathrm{S}_{\mathrm{tk}}\right)$.

The dimensionless parameter, Stokes number, defined as the ratio of the ratio of the particle stopping distance to the radius of a circular nozzle for an inertial impactor, is the governing parameter which decides if a particle will strike the impaction plate or follow the air streamlines and go out of the impaction region remaining airborne.

If $S_{\text {tk }}$ is larger then approximately unity the particle will impact on the body. Actually, the square root of Stokes number $\left(\sqrt{ } \mathrm{S}_{\mathrm{tk}}\right)$, is more commonly used since it is a dimensionless particle size. Critical value of $\sqrt{\mathrm{S}_{\mathrm{tk}}}$, often used to characterize inertial classifiers, is $\sqrt{ } \mathrm{S}_{\mathrm{tk}}$. This is the

Figure 1: Schematic view of a real impactor. 


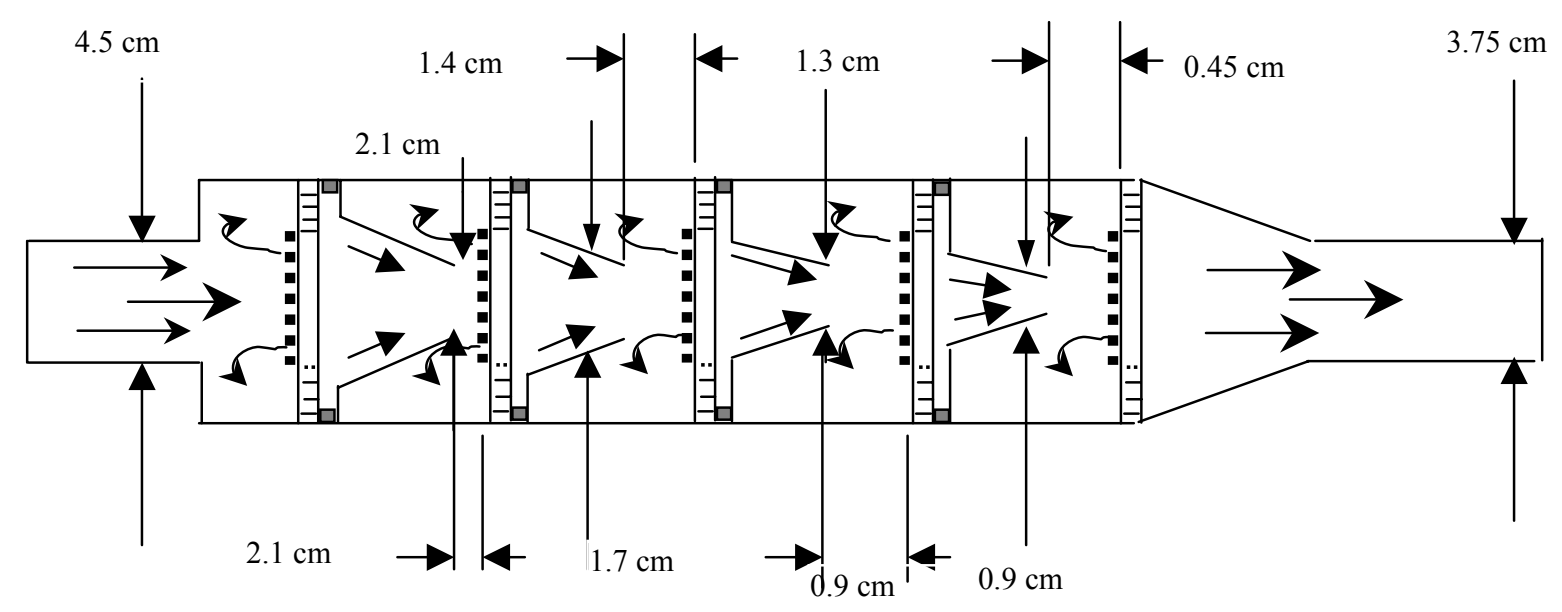

Figure 2: The designed cascade impactor.

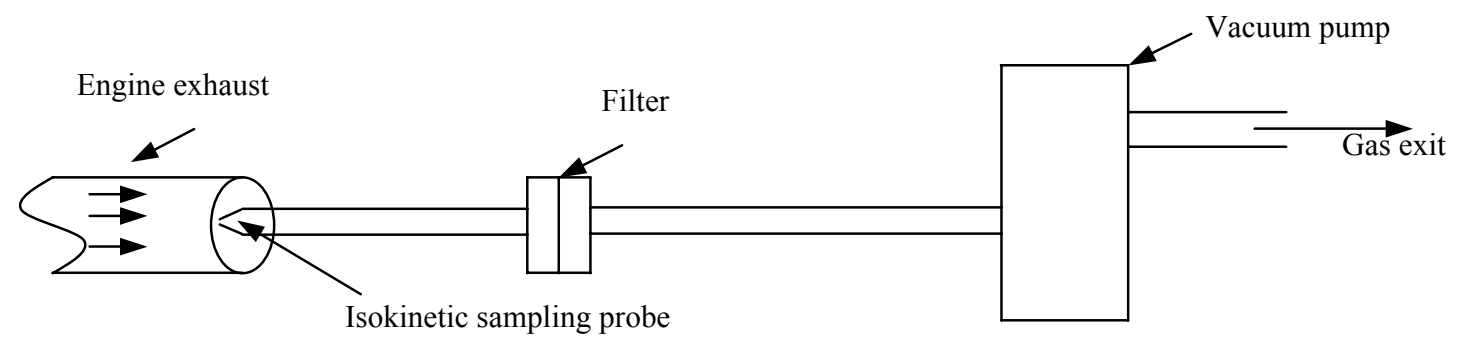

Figure 3: Efficiency measuring arrangement.

value of $\sqrt{ } S_{\text {tk }}$ corresponding to $d_{50}$, the value of particle diameter collected with $50 \%$ efficiency.

Based on earlier works and data available in literature ${ }^{6-8}$, we have designed the four stages of the cascade impactor and calculated the cut-off diameter of the particle in different stages as given in the Table 1.

The nozzle diameter (D) decreases while S/D increases in succeeding stages so that the cut-off diameter of particles decreases. The materials used for the construction of the cascade impactor are: cast iron for casing and mild steel sheet $(22,24$ and 26 gage) for

Table 1: Different dimensions of the designed virtual impactor

\begin{tabular}{ccccc}
\multicolumn{5}{c}{ impactor } \\
Stage & $\begin{array}{c}\text { Nozzle } \\
\text { Diameter, } \\
\mathrm{D}(\mathrm{cm})\end{array}$ & $\begin{array}{c}\text { Jet-to-plate } \\
\text { distance, } \\
\mathrm{S}(\mathrm{cm})\end{array}$ & $\mathrm{S} / \mathrm{D}$ & $\begin{array}{c}\text { Cut-off } \\
\text { diameter }(\mu \mathrm{m})\end{array}$ \\
\hline 1st & 2.1 & 2.1 & 1.0 & $157-174$ \\
2nd & 1.7 & 1.4 & 0.82 & $105-157$ \\
3rd & 1.3 & 0.9 & 0.7 & $43-105$ \\
4th & 0.9 & 0.45 & 0.5 & less than 43 \\
\hline
\end{tabular}

Table 2: Specification of Tested Engine

\begin{tabular}{ll}
\hline \multicolumn{1}{c}{ Items } & \multicolumn{1}{c}{ Specification } \\
\hline Model & $\begin{array}{l}\text { S 195 } \\
\text { Single cylinder, 4-stroke diesel } \\
\text { engine }\end{array}$ \\
Bore $\times$ stroke & $95 \times 115 \mathrm{~mm}$ \\
Rated output & $13.2 \mathrm{hp} / 2000 \mathrm{rpm}$ \\
Compression ratio & $20: 1$ \\
Type of cooling & Water evaporative \\
Injection pressure & $13.5 \mathrm{MPa}$ \\
\hline
\end{tabular}

collector plates and separator rings. A schematic view of the cascade impactor is shown in Figure 2.

\section{EXPERIMENTAL PROCEDURE}

The experiment was carried out on a single cylinder, 4-stroke, DI diesel engine. The specification of the engine has been given in Table 2. The experimental set up has been shown in Figure 3. The engine was operated in two modes: one, with constant speed and variable loads and the other, with constant load and variable speed. In both modes, data were taken with and without fitting the cascade impactor to the tail pipe of the engine. In both cases, a small volume of exhaust gases, sampled isokinetically, was made to pass through submicron filters and also exhaust gas analyzer with and without using the cascade impactor. Thus, the efficiency of the cascade impactor and the effect of the impactor on exhaust emissions were found out.

The effect of the cascade impactor on engine performance was also determined by calculating different engine parameters with and without using the impactor.

\section{RESULTS AND DISCUSSION}

The experimental results have been plotted in Figures 4 to 9 . The variation collection efficiency of the cascade impactor with different loads at a constant speed of 1000 $\mathrm{rpm}$ has been given in Figure 4. The figure shows that the collection efficiency decreases as the load increases. This may be due to the reason that as more particles are emitted from the engine at increased load, excess particles bounce out of impaction because the impaction plate is saturated with particles. The same trend is observed from the curve in Figure 5 which shows the effect of engine speed on 


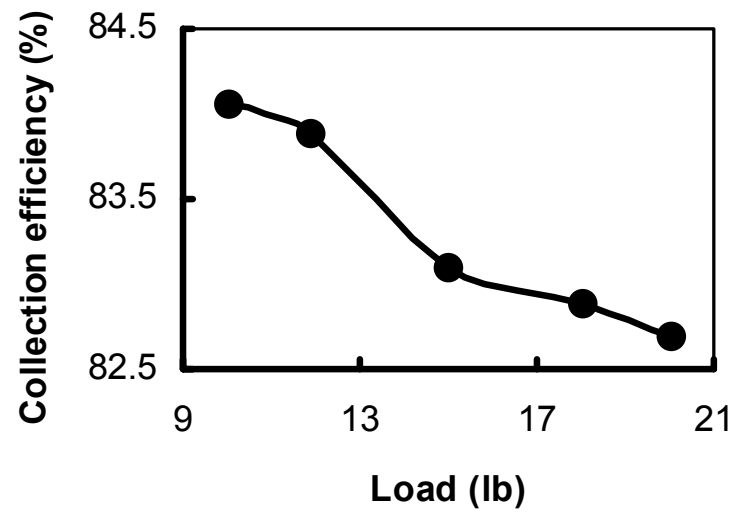

Figure 4: Variation of collection efficiency with engine load at constant engine speed.

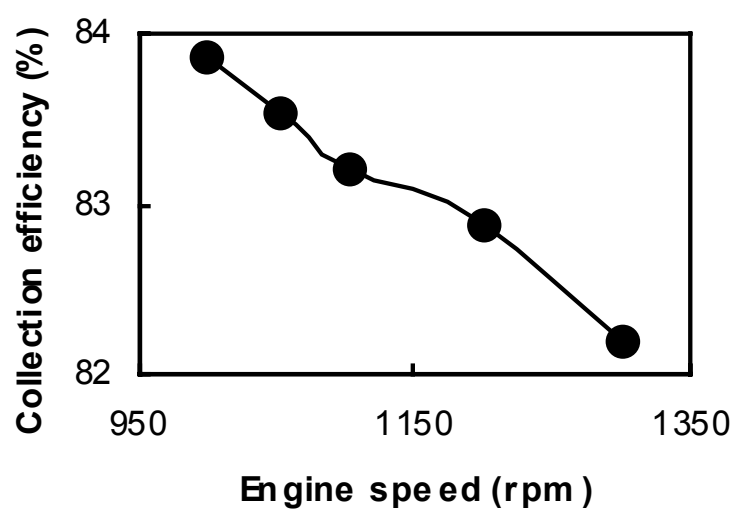

Figure 5: Variation of collection efficiency with engine speed at constant engine load.

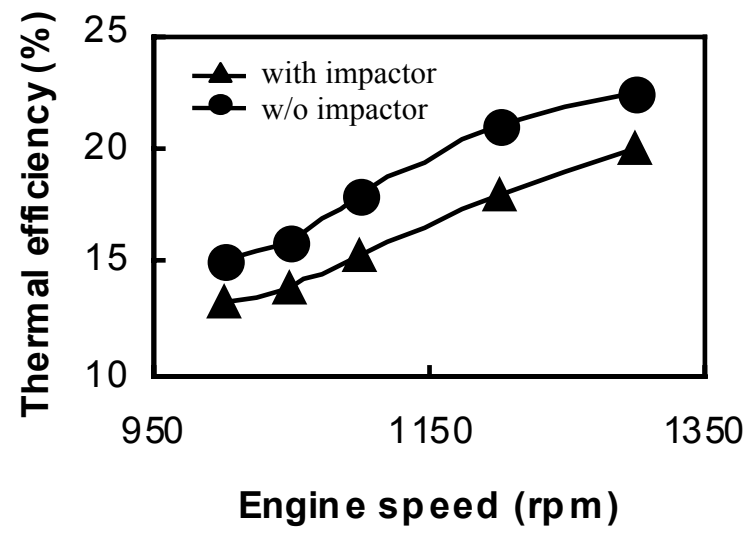

Figure 6: Variation of thermal efficiency with engine speed at constant load.

collection efficiency of the impactor at a constant load of $6 \mathrm{~kg}$. At higher speed, the engine emits more particles and the impaction plate, being saturated with particles, incapable of retaining excess particles so that the collection efficiency decreases.

Figure 6 shows the variation of brake thermal efficiency with different speeds of the engine at a constant load of $6 \mathrm{~kg}$. It is seen from the figure that as the speed increases brake thermal efficiency of the engine also increases when the cascade impactor is fitted or not fitted to the engine. However, the brake thermal efficiency of the engine is lower when the impactor is fitted to the engine to

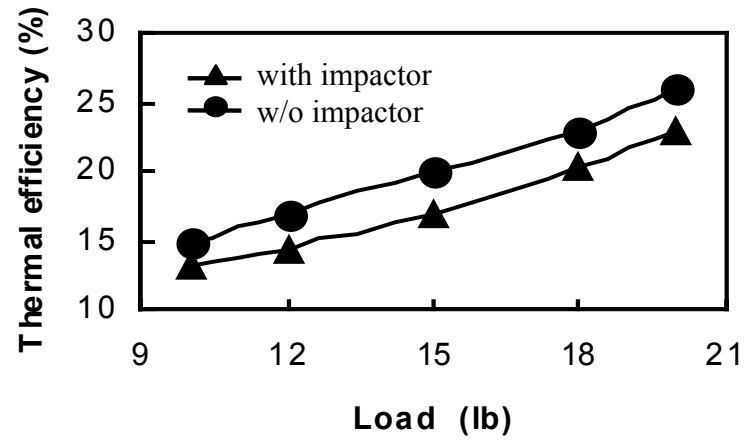

Figure 7: Variation of thermal efficiency with engine load at constant speed.

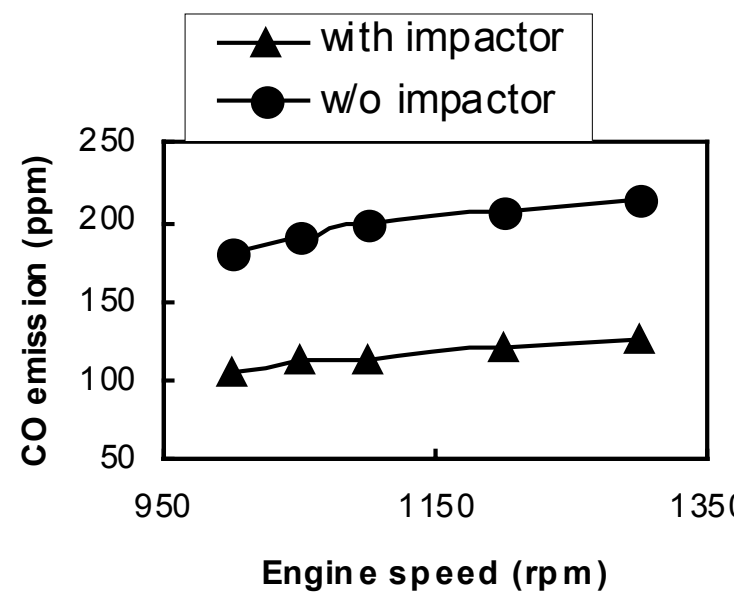

Figure 8: Variation of $\mathrm{CO}$ emission with engine speed at constant load.

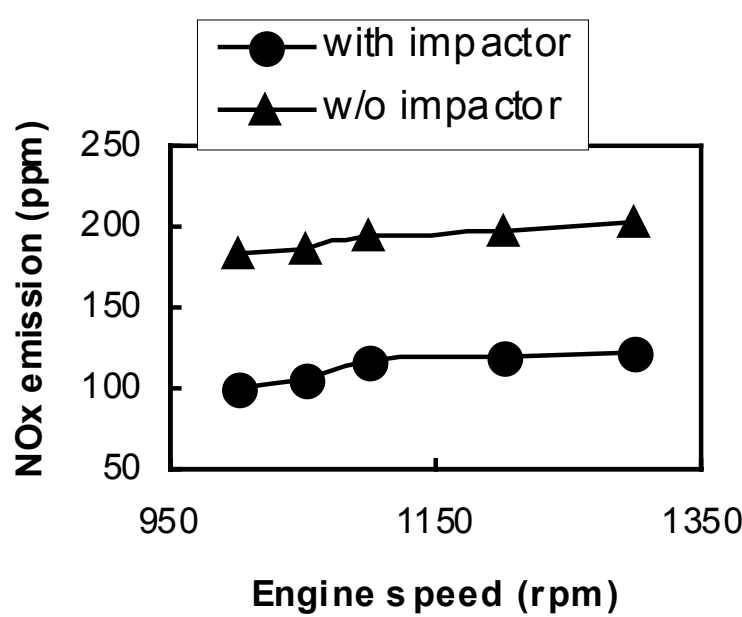

Figure 9: Variation of NOx emission with engine speed at constant load.

that when the impactor is not fitted. This may be due to the fact that more fuel is required to overcome the back pressure when the cascade impactor is fitted to the engine to develop the same power when the impactor is not fitted. The same trend is observed for the brake thermal efficiency when the engine is operated at different loads with a constant speed of $1000 \mathrm{rpm}$ with and without the cascade impactor as evident from Figure 7. 
Figures 8 and 9 give the variation of $\mathrm{CO}$ and NOx emissions respectively from the engine at different engine speeds with a constant load of $6 \mathrm{~kg}$ and when the engine is with or without the cascade impactor. It is clear for the figures that both emissions decrease when the cascade impactor is fitted to the engine. $\mathrm{CO}$ coming out of the engine reacts with the oxygen present in the impactor at high temperature and converts to $\mathrm{CO}$. This results in the reduction of $\mathrm{CO}$ coming out from the impactor exit. Reduction in NOx may be due to lesser complete combustion resulting lower temperature inside cylinder when the cascade impactor is fitted to the engine.

\section{CONCLUSIONS}

The experimental results can be summarized as follows:

i. The collection efficiency of the cascade impactor decreases with the increase of either load or speed.

ii. The brake thermal efficiency of the engine increases with the increase in load or rpm, but the same decreases when the cascade impactor is fitted to the engine exhaust pipe.

iii. The exhaust emissions of NOx and CO decrease when the cascade impactor is connected to the engine.

Thus, it can be concluded that a cascade impactor can be used to control particulate emission effectively from a diesel engine.

\section{REFERENCES}

[1] Hinds, W. C., 1982, Aerosol Technology. John Wiley and Sons, Inc., New York, USA.

[2] McClellan, R. O., 1986, American Industrial Hygiene Association Journal. Vol. 47(1), pp. 1-13.

[3] Government of India (GOI), 1999, White Paper on Pollution in Delhi With an Active Plan. Ministry of Environment and Forecasts, India.

[4] Pui, D. Y. H. and Liu, B. Y. H., 1989, TSI Journal of Particle Instrumentation. Vol. 4(2), pp. 3-20.

[5] Marple, V. A., Liu, B. Y. H. and Whitby, K.T., 1974, Journal of Fluids Engineering. December, pp. 394400.

[6[ Mercer, T. T. and Chow, H. Y., 1968, Journal of Colloidal and Interface Science. Vol. 27(1), pp. 75-83.

[7] Fernandez de la Mora, J., Hering, S.V., Rao, N. and McMurry, P. H., 1990, Journal of Aerosol Science. Vol. 21, pp. 169-187.

[8] Vanderpool, R.W., Lundgren, D. A., Marple, V. A. and Rubow, K. L., 1987, Aerosol Science and Technology. Vol. 7, pp. 177-185. 